\title{
MENINGKATKAN KEMAMPUAN SOSIAL EMOSIONAL ANAK USIA DINI MELALUI PERMAINAN MENJARING IKAN
}

\author{
Sunandar Azma'ul Hadi \\ Sekolah Tinggi Ilmu Tarbiyah Nahdlatul Ulama Al Mahsuni Lombok Timur \\ email: sunandarazmaulhadi@gmail.com
}

\begin{abstract}
This study aims to improve children's social emotional skills through fishing games in group B PAUD KB Wanting Skilled Dusun Dasan Koak. Researchers chose this game to catch fish because the game of catching fish has never been implemented in PAUD KBWants Skilled in improving children's social abilities. This type of research is qualitative research. The subjects in this study were 17 children of group B KB PAUD Want Skilled. The object of this research is the ability to interact, cooperate, and be responsible. Data collection methods used were observation, interviews, and documentation. The instrument used was the observation sheet. The data analysis technique was conducted in a descriptive qualitative manner. The results showed that the social emotional abilities of children increased after the action through fishing games. From the activity data before the research, it shows that the percentage of children's social emotional abilities is $23.52 \%$ or 4 children (BSH), $29.41 \%$ or 5 children (MB), and $47.05 \%$ or 8 children (MB). At the first meeting, the percentage of social emotional abilities increased to $29.41 \%$ or 5 children (BSB), $35.29 \%$ or 6 children (BSH), and 35.29\% or 6 children (MB). At the next meeting, the percentage of social emotional abilities increased to $41.17 \%$ or 7 children (BSB), $47.05 \%$ or 8 children (BSH), and $11.76 \%$ or 2 children (MB). The game to catch fish is carried out in groups, there are groups that act as fish and there are groups that act as fishing nets. In group formation, the researcher involved the children by drawing and assigning two children to be the leaders in each group.
\end{abstract}

Keywords: Emotional Social Ability, Fishing Game

\begin{abstract}
Abstrak : Penelitian ini bertujuan untuk meningkatkn kemampuan sosial emosional anak melalui permainan menjaring ikan di kelompok B PAUD KB Ingin Terampil Dusun Dasan Koak. Permainan menjaring dipilih peneliti karena permainan menjaring ikan belum pernah diterapkan di PAUD KB Ingin Terampil dalam meningkatkan kemampuan sosial anak. Jenis penelitian ini adalah penelitian kualitatif. Subjek pada penelitian ini adalah 17 anak kelompok B PAUD KB Ingin Terampil. Objek penelitian ini yaitu kemampuan berintraksi, bekerja sama, dan tanggung jawab. Metode pengumpulan data yang digunakan adalah observasi, wawancara, dan dokumentasi. Instrumen yang digunakan adalah lembar observasi. Teknik analisis data dilakukan secara deskriptif kualitatif. Hasil penelitian menunjukkan bahwa kemampuan sosial emosional anak meningkat setelah adanya tindakan melalui permainan menjaring ikan. Dari data kegiatan sebelum penelitian menunjukkan persentase kemampuan sosial emosional anak adalah 23,52\% atau 4 anak (BSH), 29,41\% atau 5 anak (MB), dan $47,05 \%$ atau 8 anak(MB). Pada pertemuan pertama persentase kemampuan sosial emosional
\end{abstract}


meningkat menjadi 29,41\% atau 5 anak (BSB), 35,29\% atau 6 anak (BSH), dan 35,29\% atau 6 anak (MB). Pada pertemuan selanjutnya persentase kemampuan sosial emosional meningkat menjadi 41,17\% atau 7 anak (BSB), 47,05\% atau 8 anak (BSH), dan 11,76\% atau 2 anak (MB). Permainan menjaring ikan dilakukan secara berkelompok, ada kelompok yang berperan sebagai ikan dan ada kelompok yang berperan sebagai jaring ikan. Dalam pembentukan kelompok, peneliti melibatkan anak-anak dengan cara diundi dan menunjuk dua anak untuk menjadi pemimpin dimasing-masing kelompok.

Kata Kunci : Kemampuan Sosial Emosional, Permainan Menjaring Ikan

\section{PENDAHULUAN}

Pendidikan Anak Usia Dini (PAUD) merupakan jenjang pendidikan sebelum anak memasuki pendidikan dasar yang berperan membina peserta didik usia 0-6 tahun untuk mengoptimalkan aspek-aspek perkembangannya. Menurut UU Nomor 27 Tahun 1999, Bab 1 Pasal 1, menyatakan bahwa Pendidikan Anak Usia Dini merupakan salah satu bentuk penyelenggaraan pendidikan yang secara spesifik bertujuan mengoptimalkan pertumbuhan dan perkembangan yang meliputi fisik motorik, kognitif, sosial emosional (sikap, prilaku, serta agama), bahasa, moral, dan seni, sesuai dengan keunikan dan tahap-tahap perkembangan yang dilalui oleh anak usia dini ${ }^{1}$. Selain itu Pendidikan Anak Usia Dini berperan penting terhadap perkembangan kepribadian anak serta mempersiapkan anak untuk memasuki jenjang pendidikan selanjutnnya. Pasal 1 Ayat 14 Undang-Undang No. 20 Tahun 2003 tentang Sistem Pendidikan Nasional menegaskan bahwa Pendidikan Anak Usia Dini adalah suatu upaya pembinaan yang ditujukan kepada anak sejak lahir sampai dengan usia enam tahun yang dilakukan melalui pemberian rangsangan pendidikan untuk membantu pertumbuhan dan perkembangan jasmani dan rohani agar anak memiliki kesiapan dalam memasuki pendidikan pada jenjang yang lebih tinggi.

Tugas perkembangan merupakan tugas yang timbul pada satu periode kehidupan tertentu. Keberhasilan yang diperoleh pada tugas perkembangan tersebut akan menimbulkan kebahagiaan dan mempengaruhi keberhasilan pada tugas perkembangan lainya, sedangkan kegagalan menimbulkan keditakbahagiaan dan

${ }^{1}$ Hasan, Maemunah. Pendidikan Anak Usia Dini. (Jogjakarta: Diva Press. 2011) 
ketidaksetujuan masyarakat, serta kesulitan dalam melaksanakan tugas perkembangan lainnya. Oleh karena itu Pendidikan Anak Usia Dini memiliki peran yang penting dalam membantu mengoptimalkan pertumbuhan dan perkembangan anak, termasuk perkembangan sosial emosionalnya.

Menurut Hurlock 1980, menyatakan bahwa hanya ada sedikit bukti yang menyatakan sikap sosial atau antisosial merupakan sikap bawaan, kemampuan tersebut tergantung pada pengalaman-pengalaman sosial. Kehidupan awal anak berpusat di sekitar rumah, maka di rumahlah diletakkan dasar prilaku dan sikap sosial. Jadi anak merupakan makhluk sosial yang tidak bisa hidup sendiri (zoon politicon) dan agar anak mampu menjalin hubungan yang baik dengan orang lain, maka orang tua dan guru memiliki peran penting untuk mengembangkan kemampuan sosial emosional anak. Kemampuan sosial emosional anak merupakan kemampuan yang harus dimunculkan, dilatihkan serta dikembangkan melalui pembinaan, pembiasaan dan pengajaran sejak dini seperti halnya di PAUD, TK, RA dan sederajat ${ }^{2}$.

Anak yang memiliki kemampuan sosial yang baik dapat dilihat dari seberapa dekat dia bisa berteman atau bersahabat, seberapa mudah dia akrab dengan orang asing dan jarang memiliki konflik dengan temannya. Anak yang memiliki kemampuan sosial yang rendah menunjukkan sebaliknya, yaitu anak seperti kekurangan teman atau sering menyendiri, sulit untuk akrab dengan orang asing dan sering mengalami konflik dengan temannya. Pada dasarnya anak ini bukanlah anak yang nakal yang tidak memiliki perasaan, tetapi hanya memperlihatkan tanda tanda kemampuan sosial yang kurang berkembang secara maksimal.

Perkembangan sosial emosional merupakan proses belajar menyesuaikan diri dengan suatu kelompok, belajar bekerja sama, dan berintraksi dengan lingkungan sekitarnya dan kemampuan seseorang dalam memahami dan menjalin suatu hubungan dengan masyarakat ${ }^{3}$.

Berdasarkan hasil observasi awal saat proses pembelajaran di kelompok B Paud Ingin Terampil Dasan Koak Desa Mekar Sari, terdapat beberapa permasalahan pada saat proses belajar mengajar berlangsung, diantaranya yaitu kegiatan belajar sehari-

${ }^{2}$ Hurlock, E.B. Perkembangan Anak. (Jakarta : Erlangga. 1978)

${ }^{3}$ Santi, D. Pendidikan Anak usia Dini Antara Teori Dan Praktek. (Jakarta: PT. Indeks. 2009) 
hari lebih sering dengan kegiatan individual dan dalam meningkatkan aspek perkembangan sosial emosional guru hanya menggunakan LKA (Lembar Kerja Anak) yang di dalamnya terdapat gambar yang berkaitan dengan sosial emosional anak. Proses pembelajaran juga lebih mengedepankan aspek perkembangan kognitif seperti membaca dan berhitung, karna anak yang kemampan kognitifnya sesuai dengan apa yang diharapkan orang tua/wali murid, maka hal tersebut akan membuat bangga menyekolahkan anak-anaknya di PAUD KB Ingin Terampil Dusun Dasan Koak dan lebih parahnya juga adanya seleksi masuk SD harus bisa membaca dan menulis serta memiliki ijazah PAUD/TK/RA/Sederajat. Akibatnya PAUD KB Ingin Terampil Dusun Dasan Koak lebih mengedepankan aspek perkembangan kognitif sementara aspek perkembangan sosial emosional kurang diperhatikan.

Berdasarkan observasi di atas menunjukkan bahwa kemampuan sosial emosional anak belum sesuai dengan pencapaian perkembangan anak. Hal ini dibuktikan dari 17 anak di kelas hanya terdapat 23,52\% atau 4 anak yang sosial emosional cukup baik yang sesuai dengan tingkat pencapaian perkembangan anak usia dini, 29,41\% atau 5 anak yang sosial emosional mulai berkembang, dan 47,05\% atau 8 anak yang sosial emosional masih perlu dikembangkan.

Dari hasil wawancara dengan kepala sekolah dan wali kelas kelompok B yang dilaksanakan pada saat peneliti melakukan observasi awal didapatkan hasil bahwa permainan menjaring ikan sebagai upaya untuk meningkatkan kemampuan sosial emosional anak belum pernah dilakukan di PAUD KB Ingin Terampil Dasan Koak. Dari berbagai permasalahan tersebut, maka peneliti merasa perlu untuk melakukan perbaikan terhadap pembelajaran dalam meningkatkan kemampuan sosial emosional anak melalui permainan menjaring ikan.

Permainan menjaring ikan adalah permainan yang dilakukan secara berkelompok, masing-masing kelompok memiliki peran dan memiliki bagian-bagian untuk dikerjakan bersama sehingga dapat mencapai tujuan dari permainan. Permainan menjaring ikan melatih anak untuk saling bekerja sama antar kelompok, melatih anak untuk saling berintraksi dengan temannya, melatih anak untuk punya rasa tanggung jawab atas tugas yang telah diberikan, dan memiliki rasa empati 
terhadap orang lain ${ }^{4}$. Oleh karena itu dengan penelitian ini diharapkan adanya peningkatan kemampuan sosial emosional anak melalui permainan menjaring ikan.

Dari hasil penelitian yang dilakukan oleh Novita Sari tahun 2015 dengan judul Peningkatan Keterampilan Sosial Anak Melalui Permainan Menjala Ikan Pada Kelompok B PAUD Permata Bunda Desa Air Pikat, berdasarkan dari hasil penelitian tersebut menunjukan bahwa permainan menjala ikan dapat meningkatkan perkembangan keterampilan anak dengan skor rata-rata keterampilan anak 45\% pada siklus 1 dan meningkat pada siklus ke II menjadi 85\% ${ }^{5}$.

Dari hasil penelitian yang dilakukan oleh Muthmainnah tahun 2016 yang berjudul Pelatihan Permainan Menjala Ikan Untuk Meningkatkan Perkembangan Sosial Emosional Anak. Berdasarkan hasil penelitian, diperoleh hasil bahwa para guru TK tampak antusias dalam melakukan permainan sehingga suasana kelas menjadi hidup dan lebih menyenangkan. Dengan adanya simulasi permainan, diharapkan para guru-guru TK dapat memperaktikan dan mengembangkan permainan di sekolah masing-masing.

Berdasarkan penelitian yang telah dilakukan oleh Novita Sari dan Muthmainnah menayatakan sangat besar kemungkinannya bahwa permainan menjaring ikan dapat meningkatkan kemampuan sosial emosional anak, dan peneliti sendiri tertarik untuk melakukan penelitian karena permainan menjaring ikan dengan menggunakan metode bermain secara kelompok yang dimana metode tersebut belum pernah dicoba di Kelompok B PAUD KB Ingin Terampil Dasan Koak.

\footnotetext{
${ }^{4}$ Nugraha, A. \& Rachmawati, Y. Metode Pengembangan Sosial Emosional. (Jakarta : Universitas Terbuka. 2005)

5 Sari, Novita. Peningkatan Keterampilan Sosial Anak Melalui Permainan Menjala Ikan. (Medan: Universitas Negeri Medan. 2015)

6 Muthmainnah. Pelatihan Pengembangan Permainan Menjala ikan Untuk Meningkatkan Perkembangan Sosial Emosional Anak. (Universitas Yogyakarta. Jurnal Pendidikan, Vol 5, No 2. 2016)
} 


\section{METODE PENELITIAN}

Jenis penelitian ini adalah penelitian kualitatif, dimana penelitian ini berdasarkan pada kondisi objek yang alamiah, dinamis dan pemikiran secara utuh (bolistic) yakni mempunyai satu kesatuan yang tidak dapat dipisahkan ${ }^{7}$. Hal yang menjadi pokok kevalidan dalam memperoleh data, adalah kehadiran peneliti yang cukup dilokasi penelitian untuk bisa menentukan berbagai metode yang tepat dalam memperoleh data dan hasil penelitian yang memuaskan.

Penelitian ini dilaksanakan pada Tanggal 10 - 21 Februari 2020 yang berlokasi di Kelompok B PAUD KB Ingin Terampil Dasan Koak Desa Mekar Sari. Sumber data dalam penelitian ini adalah hasil observasi dan wawancara sebagai data primernya. Adapun data sekunder dalam penelitian ini diperoleh melalui hasil dokumentasi yang diperoleh dari pihak sekolah dan pihak lain yang relevan.

Data yang diperoleh dalam penelitian ini selanjutnya dianalisis dengan metode deskriptif analitik, yaitu dengan cara data yang telah dikumpulkan awalnya disusun, dan kemudian dianalisa sesuai dengan penelitian yang bersifat diskriptif maka untuk menganalisa data perlu melalui tahapan reduksi data, penyajian data, dan penarikan kesimpulan.

\section{HASIL DAN PEMBAHASAN}

Berdasarkan hasil observasi, peneliti menemukan bahwa kondisi awal di PAUD KB Ingin Terampil Dusun Dasan Koak ditemukan 23,52\% atau 4 anak yang sosial emosionalnya cukup baik yang sesuai harapan, 29,41\% atau 5 anak yang sosial emosionalnya mulai berkembang, dan 47,05\% atau 8 anak yang sosial emosionalnya masih perlu dikembangkan.

Adapun hasil peningkatan kemampuan sosial emosional anak melalui permainan menjaring ikan setiap kali pertemuan mengalami peningkatan dimana pada pertemuan pertama yang dapat dilihat pada tabel 1:

\footnotetext{
${ }^{7}$ Sugiyono. Metode Penelitian Pendidikan : Kuantitatif, Kualitatif, Dan R \& D. (Bandung: Alfabeta. 2013)
} 
Tabel 1. Kemampuan Sosial Emosional Anak Pertemuan Pertama

\begin{tabular}{llcccc}
\hline \multirow{2}{*}{ No } & \multicolumn{1}{c}{ Nama } & Intraksi & $\begin{array}{c}\text { Bekerja } \\
\text { sama }\end{array}$ & $\begin{array}{c}\text { Bertanggung } \\
\text { jawab }\end{array}$ & $\begin{array}{c}\text { Kemampuan } \\
\text { Sosial } \\
\text { emosional }\end{array}$ \\
\cline { 2 - 5 } & Ahmad Mariadi & BSH & BSH & BSH & BSH \\
\hline 2 & Aisya Fatin Humaira & MB & BSH & BSH & BSH \\
\hline 3 & Aninisa Kamila & MB & BB & MB & MB \\
\hline 4 & Fatin Syahira & BB & MB & BB & BB \\
\hline 5 & Faqih Zauja & BB & BB & MB & BB \\
\hline 6 & Hamzan Wadi & BB & MB & MB & MB \\
\hline 7 & Indra Permata Sari & BB & MB & BB & BB \\
\hline 8 & Juhana & BSH & BSH & MB & BSH \\
\hline 9 & M. Haikal Adilal & MB & MB & MB & MB \\
\hline 10 & M. Wido & BB & BB & MB & BB \\
\hline 11 & M. Dika Almahfuz & MB & MB & BB & MB \\
\hline 12 & M. Aditya Al-faqih & BSH & BSH & BSH & BSH \\
\hline 13 & Piaril Mayani & MB & BSH & BSH & BSH \\
\hline 14 & Ridho Halwatun N. & MB & MB & MB & MB \\
\hline 15 & Reza Ardiansyah & BB & MB & MB & MB \\
\hline 16 & Suci Olivia & BB & BB & BB & BB \\
\hline 17 & Zahratul Aini & BB & BB & BB & BB \\
\hline
\end{tabular}

Dari tabel 1 dapat kita lihat bahwa pada pertemuan pertama sudah terlihat adanya peningkatan kemampuan sosial emosional anak dibandingkan sebelum melakukan penelitian yang dimana jumlah tingkat kemampuan sosial emosional anak sebanyak 4 orang anak dengan persentase 23,52\% memiliki tingkat kemampuan tinggi sedangkan 5 anak dengan persentase 29,41\% dengan tingkat kemampuan sedang, dan 8 anak dengan persentase 47,05\% dengan kemampuan rendah rendah. 
Tabel 2. Kemampuan Sosial Emosional Anak Pertemuan ke dua

\begin{tabular}{lllccc}
\hline \multirow{2}{*}{ No } & \multicolumn{1}{c}{ Nama } & Intraksi & $\begin{array}{c}\text { Bekerja } \\
\text { sama }\end{array}$ & $\begin{array}{c}\text { Bertanggung } \\
\text { jawab }\end{array}$ & $\begin{array}{c}\text { Kemampuan } \\
\text { Sosial } \\
\text { emosional }\end{array}$ \\
\cline { 3 - 5 } 1 & Ahmad Mariadi & BSB & BSH & BSH & BSH \\
\hline 2 & Aisya Fatin Humaira & BSB & BSB & BSB & BSB \\
\hline 3 & Aninisa Kamila & BSB & BSB & BSH & BSB \\
\hline 4 & Fatin Syahira & BSH & BSH & MB & BSH \\
\hline 5 & Faqih Zauja & MB & MB & BSH & MB \\
\hline 6 & Hamzan Wadi & BSB & BSB & BSB & BSB \\
\hline 7 & Indra Permata Sari & BSH & BSH & MB & BSH \\
\hline 8 & Juhana & BSB & BSB & BSB & BSB \\
\hline 9 & M. Haikal Adilal & BSB & BSB & BSH & BSB \\
\hline 10 & M. Wido & BSH & MB & BSH & BSH \\
\hline 11 & M. Dika Almahfuz & BSB & BSB & BSH & BSB \\
\hline 12 & M. Aditya Al-faqih & BSH & BSH & BSH & BSH \\
\hline 13 & Piaril Mayani & BSB & BSB & BSH & BSB \\
\hline 14 & Ridho Halwatun N. & BSH & BSH & MB & BSH \\
\hline 15 & Reza Ardiansyah & BSH & BSH & BSH & BSH \\
\hline 16 & Suci Olivia & BSH & MB & BSH & BSH \\
\hline 17 & Zahratul Aini & BSH & MB & MB & MB \\
\hline
\end{tabular}

Berdasarkan analisis yang dilakukan oleh peneliti dapat dilihat bahwa peningkatan kemampuan sosial anak di pengaruhi oleh permainan menjaring ikan. Melalui permainan menjaring ikan, kemampuan berintraksi, bekerja sama, dan bertanggung jawab sudah mengalami peningkatan. Anak yang awalnya pendiam, suka menyendiri, kini sudah dapat berkembang dari sebelumnya. Hal ini dapat dilihat ketika anak antusias dalam mengikuti permainan menjaring ikan.

Selain melalui permainan menjaring ikan, keberhasilan peningkatan kemampuan sosial anak ini juga dipengaruhi oleh metode peneliti dan guru dalam mengatasi kesulitan yaitu dengan cara melibatkan anak dalam pembentukan kelompok supaya anak tidak pilih-pilih teman yaitu dengan cara mengambil undian 
supaya anak merasa bahwa kelompok tersebut terbentuk karna partisipasinya dan anak lebih mudah diatur dalam melaksanakan tugas masing-masing dalam permainan, dan selain itu juga pembentukan kelompok yang melibatkan anak dengan cara mengambil undian sendiri-sendiri dapat membentuk kelompok yang beragam yaitu baik dengan tingkat kemampuan yang berbeda-beda, kecerdasan, bahkan jenis kelamin. Hal ini dapat menghapus kemungkinan anak plih-pilih teman kelompok, dan ini dikuatkan oleh Nur Asmi, bahwa mencampurkan anak berdasarkan prestasi dan kecerdasan dapat membangun sistem kultur teman sebaya, sedangkan mencampur anak berdasarkan etnik dan jenis kelamin dapat membawa perspektif unik dalam kelompok.

Tindakan selanjutnya dalam permainan menjaring ikan setelah terbentuknya kelompok adalah menentukan pemimpin dalam setiap kelompok. Guru menunjuk satu anak dari masing-masing kelompok untuk menjadi pemimpin di setiap kelompok. Hal ini sesuai dengan pendapat Sukmawati, bahwa salah satu kelebihan kerja kelompok adalah dapat mengembangkan bakat kepemimpinan dan mengajarkan keterampilan berdiskusi.

Adapun hasil peningkatan kemampuan anak pada setiap pertemuan dapat dilihat pada tabel 1 dan 2, walaupun pada pertemuan pertama tidak terlalu terjadi peningkatan yang signifikan, hal ini disebabkan karena pada awal-awal pertemuan tidak terlalu antusias dikarenakan guru dan peneliti masih belum menemukan metode dalam pembentukan kelompok. Setelah peneliti mencoba melakukan penelitian lagi dan melibatkan anak dalam pemebentukan kelompok serta membentuk pemimpin dalam setiap kelompok, kemampuan sosial emosional anak sudah terlihat ditambah lagi permainan dilakukan di tempat yang berbeda seperti luar dan di dalam ruangan. Peningkatan kemampuan sosial emosional anak juga disini mengalami peningkatan yang sangat signifikan yaitu sebesar $80 \%$, hal ini disebabkan adanya pemberian motivasi selama melakukan penelitian sehingga anak sangat antusias mengikuti permainan. 


\section{KESIMPULAN}

1. Melalui permainan menjaring ikan dapat meningkatkan kemampuan sosial emosional pada anak usia dini. Terbukti dengan adanya peningkatan yang sangat signifikan mencapai $80 \%$ atau 15 anak yang sosial emosionalnya sesuai dengan tingkat pencapaian perkembangan yaitu dari total 17 anak di PAUD KB Ingin Terampil. Oleh karena itu permainan menjaring ikan dapat meningkatkan kemampuan sosial emosional anak. Hal ini dikarenakan permainan menjaring ikan dapat melatih kemampuan anak seperti kemampuan berintraksi, bekerja sama, dan bertanggung jawab atas yang diberikan guru.

2. Adanya kesulitan-kesulitan pada saat pembentukan kelompok disebabkan karena anak masih memilih teman kelompok dalam permainan. Setelah peneliti melakukan penelitian dengan melibatkan anak dalam pembentukan kelompok dan menentukan pemimpin dalam setiap kelompok. Hal ini menambah antusias anak dalam mengikuti permainan serta pemberian reward tepuk salut dapat mengatasi kesulitan-kesulitan yang guru dan peneliti temukan.

\section{SARAN}

1. Kepala sekolah dapat menjadi motor penggerak dalam perbaikan terhadap proses pembelajaran dan sebaiknya menjaga hubungan baik antara kepala sekolah dan guru melalui kerja kolaborasi.

2. Pihak sekolah harus dapat menciptakan kondisi belajar yang memadai dengan memperhatikan fasilitas dan sarana prasarana sekolah yang menunjang dalam pembelajaran khususnya pembelajaran yang dapat meningkatkan kemampuan sosial emosional anak seperti media permainan, dan alat-alat pembelajaran yang lain.

3. Guru kelas harunya bisa mengoptimalkan kegiatan permainan dengan menggunakan media permainan yang menarik, dan melibatkan anak dalam pembentukan kelompok sebelum bermain, supaya anak antusias dalam mengikuti peroses pembelajaran. 
4. Guru kelas yang lain hendaknya melakukan pendekatan secara emosional terhadap anak, agar anak tidak merasa minder, takut, dan selalu siap dalam mengikuti permainan.

5. Latar permainan di setting semenarik mungkin sehingga memberikan nuansa yang berbeda dalam permainan, dengan begitu akan menghilangkan rasa bosan anak pada saat mengikuti permainan

\section{DAFTAR PUSTAKA}

Hasan, Maemunah. (2011). Pendidikan Anak Usia Dini. Jogjakarta: Diva Press.

Hurlock, E.B. (1978a). Perkembangan Anak. Jakarta : Erlangga.

Muthmainnah. (2016). Pelatihan Pengembangan Permainan Menjala ikan Untuk Meningkatkan Perkembangan Sosial Emosional Anak. Universitas Yogyakarta. Jurnal Pendidikan, Vol 5, No 2.

Nugraha, A. \& Rachmawati, Y. (2005). Metode Pengembangan Sosial Emosional. Jakarta : Universitas Terbuka.

Sari, Novita. (2015). Peningkatan Keterampilan Sosial Anak Melalui Permainan Menjala Ikan. Medan: Universitas Negeri Medan.

Santi, D. (2009). Pendidikan Anak usia Dini Antara Teori Dan Praktek. Jakarta: PT. Indeks.

Sugiyono. (2013). Metode Penelitian Pendidikan : Kuantitatif, Kualitatif, Dan R \& D. Bandung: Alfabeta. 